\title{
Diversity Analysis and Identification of Promising Powdery Mildew Resistance Genotypes in Field Pea (Pisum sativum L.)
}

\author{
Kedir Yimam Assen \\ High Land Pulse Improvement Division, Ethiopian Institute of Agricultural Research, Kulumsa Agricultural Research Center, Asella, \\ Ethiopia
}

Email address:

kediryimam95@gmail.com

\section{To cite this article:}

Kedir Yimam Assen. Diversity Analysis and Identification of Promising Powdery Mildew Resistance Genotypes in Field Pea (Pisum sativum L.). American Journal of Biological and Environmental Statistics. Vol. 6, No. 1, 2020, pp. 7-16. doi: 10.11648/j.ajbes.20200601.12

Received: February 25, 2020; Accepted: March 9, 2020; Published: May 15, 2020

\begin{abstract}
In the present study, seventy-one field pea gene pools including three released varieties were evaluated in an augmented block design for assessing genetic divergence and level of resistance to powdery mildew for exploitation in a breeding program aimed at improving yield potential of field pea by using cluster and principal component analysis. Among the 10 studied traits, four (Eigenvalue $>1.0$ ) contributed more than $68.45 \%$ variability among the materials. Cluster analysis grouped the 71 field pea genotypes into seven distinct classes. The genetic divergence between all possible pairs of clusters were highly significant $(\mathrm{P}<0.01)$. The inter-cluster $\mathrm{D}^{2}$ value ranged from 311.63 to 2850.61 indicated that the evaluated gene pools were highly divergent. The genetically more divergent materials present in cluster five and six as indicated by intercluster distance value (2850.61). Selecting genotypes of these clusters and crossing them probably provide promising recombinants and better sergeants for future breeding program. Considerable variation was also found for resistance against the powdery mildew diseases. Out of the total 71 genotypes 12 were resistant, 29 were moderately resistant, 25 were moderately susceptible and 5 were susceptible to powdery mildew disease. Among 12 resistant genotypes; GPHA-9 and GPHA-19 were high yielder and GPHA-29, GPHA-48, GPHA-45 and GPHA-42 genotypes were found to be high yielding among 29 moderately resistant genotypes. The resistant genotypes identified could be exploited directly and/or may be transferred through hybridization to high yielding disease susceptible genotypes after checking their yield and disease stability in a number of locations and seasons for more confirmation with the present finding, since the present result was from one location and one season (year) data.
\end{abstract}

Keywords: Cluster, Diversity, Pisum sativum, Powdery Mildew, Principal Component, Resistance

\section{Introduction}

Pulses are the second most important crops after cereals in the world's crop production. Among pulses, field pea (Pisum sativum L.) is one of the most widely cultivated crop in the world with annual production of 16205448 tonnes produced on 8141031 ha with productivity of 1.99 t/ha [8]. The top field pea-producing countries include Canada, Russian Federation, China, Ukraine, India, United States of America, France, Australia, Ethiopia and Germany [8].

Field pea ranks fourth next to faba bean, haricot bean and chickpea among pulse crops in Ethiopia in terms of total production and areas coverage [6]. It is grown on 220,508.39 hectares of land with total production of 368,519.065 tonnes and productivity of $1.671 \mathrm{t} / \mathrm{ha}$. Field pea accounts $13.79 \%$ from pulses total area coverage and $12.37 \%$ from total production in Ethiopia. [6]. It is widely cultivated in potential mid and high altitude areas in different parts of the country at elevations of 1800-3000 m with 700-1100 mm annual rainfall.

Even though wild and primitive forms of field pea species are known to exist; $P$. sativum is more dominant in the production system at the high land of the country [15].

Ethiopia, Western and Central Asia and the Mediterranean region are proposed as possible centers of origin of field pea because of the high pea genetic diversity sampled in these regions [13]. 
Field pea has a major economic advantage in the livelihood of the farming societies of the country. It is an important crop consumed in different forms with high protein content as a complement to cereals for the majority of the poor population, especially for those who cannot afford to use proteins from animal source. It contains high protein content, favorable amino acids composition and low trypsin inhibitor levels and there by supply the essential nutrients to various age groups [4]. It serves as a break crop suitable for rotation in areas where cereal monocropping is abundant due to its high atmospheric nitrogen fixing capacity.

Even if it has huge importance, the national average productivity of the country $\left(1.67 \mathrm{t} \mathrm{ha}^{-1}\right)$ is low compared with a number of cereals in the country [6] and advanced field pea producing countries in the world [8]. This is primarily due to inherent low yielding potential of the indigenous cultivars, biotic factors (diseases like powdery mildew and Ascochyta blight, insect pest, weed etc.) and abiotic (frost) factors, inadequate land allocation, poor attention for the crop, instability of cultivars, poor adaptation and poor crop management $[20,3,22,1]$.

Fungal diseases are important factors limiting the production of food-legume crops as a whole and field pea specifically in Ethiopia [17].

Powdery mildew (Erysiphe polygoni) and Ascochyta blight (Ascochyta pisi) are the major fungal diseases causing substantial yield loss $[22,1]$.

Powdery mildew is caused by the biotrophic, ascomycete fungus Erysiphe polygoni; which form colonies on leaves, stems and pods and the disease is severe in many areas of the world, particularly in climates with warm, dry days and cool nights [10].

According to [18] Powdery mildew disease affects the yield potential, causing $86 \%$ loss in field pea germplasm growing in different parts of the world. $20-30 \%$ of field pea yield reduction has been reported by powdery mildew disease in the mid-altitudes under moderate severity. Powdery mildew is a troublesome disease when days are warm and dry; nights are cool enough for dew formation.

It causes yield loss up to $37 \%$ in Ethiopia. This disease is of less effect in high rainfall areas of Ethiopia where its spores are removed from the plant tissue by rain and cannot cause infection. However, late sown and off-season fields were reported to be severely affected by the disease [16].

$21.09 \%$ of yield losses have been reported due to powdery mildew severity on local field pea cultivar from plot without fungicide application at Sinana South Eastern Ethiopia [22].

Farmers often use chemical agents for controlling the disease, which may cause environmental pollution [5].

Spore release also can cause breathing and allergic reactions in farm workers [7]. It is better to seek other alternative means of disease control methods due to high cost of fungicides, social and health related and environmental impacts. Genetic based resistance is the best option for crop breeding [9].

There is a requirement for improvement and to develop high yielding and powdery mildew resistant varieties to maximize and sustain production and productivity of field pea under small scale farmers [10].

Genetic diversity is an essential factor that determines expectation of yield improvement in the future. Knowledge of genetic diversity within a crop and association among the yield contributing characters is important for the long-term success of a breeding program and enhances the exploration of germplasm resources [19]. Evaluation of genetic diversity is essential to identify the source of genetic materials for an individual trait within the available germplasm [23]. Diversity analysis is a useful tool to identify the degree of divergence among the biological populations at genotypic level and to determine the relative contribution of different components to the total divergence both inters and intra cluster levels [12]. Therefore, the present study was undertaken to assess the genetic divergence of important morpho-agronomic traits, and to evaluate the performance of different genotypes of field pea and thereby to identify powdery mildew resistant materials evaluated under natural infection for future breeding program.

\section{Materials and Methods}

\subsection{Experimental Site}

Field experiment was carried out at Kulumsa Agricultural Research Center during the main cropping season (June to November) of the year $2018 / 19$. The center is located at 80 01 ' 10 'N latitude and 390 09'13" E longitudes and at an altitude of 2200 meter above sea level.

The agro-ecology of the Experimental site is characterized by an average annual rain-fall of $850 \mathrm{~mm}$, with short rain between March and April and long rain between June and September, and with annual mean minimum and maximum temperatures of $7.9^{\circ} \mathrm{C}$ and $23.1^{\circ} \mathrm{C}$ respectively. Kulumsa is hot spot area for powdery mildew disease occurrence under natural infection.

\subsection{Experimental Materials}

Seventy one field pea materials including Sixty-eight single plant selected from bulked gene pool field pea materials and three released varieties were considered for the study (Table 1). The three commercial varieties (letu, adi and megeri) that were included in the study which were released as moderate resistance to powdery mildew.

Table 1. List of field pea genotypes.

\begin{tabular}{lll}
\hline No & Genotype & Origin/Remark \\
\hline 1 & GPHA-36 & SPS \\
2 & GPHA-3 & SPS \\
3 & GPHA-38 & SPS \\
4 & GPHA-68 & SPS \\
5 & GPHA-2 & SPS \\
6 & GPHA-58 & SPS \\
7 & GPHA-17 & SPS \\
8 & GPHA-7 & SPS \\
9 & GPHA-60 & SPS \\
10 & GPHA-11 & SPS \\
\hline
\end{tabular}




\begin{tabular}{|c|c|c|}
\hline No & Genotype & Origin/Remark \\
\hline 11 & GPHA-42 & SPS \\
\hline 12 & GPHA-48 & SPS \\
\hline 13 & GPHA-37 & SPS \\
\hline 14 & GPHA-15 & SPS \\
\hline 15 & GPHA-10 & SPS \\
\hline 16 & GPHA-67 & SPS \\
\hline 17 & GPHA-52 & SPS \\
\hline 18 & GPHA-1 & SPS \\
\hline 19 & GPHA-33 & SPS \\
\hline 20 & GPHA-8 & SPS \\
\hline 21 & GPHA-49 & SPS \\
\hline 22 & GPHA-21 & SPS \\
\hline 23 & GPHA-12 & SPS \\
\hline 24 & GPHA-14 & SPS \\
\hline 25 & GPHA-16 & SPS \\
\hline 26 & GPHA-39 & SPS \\
\hline 27 & GPHA-55 & SPS \\
\hline 28 & GPHA-9 & SPS \\
\hline 29 & GPHA-22 & SPS \\
\hline 30 & GPHA-20 & SPS \\
\hline 31 & GPHA-31 & SPS \\
\hline 32 & GPHA-5 & SPS \\
\hline 33 & GPHA-66 & SPS \\
\hline 34 & GPHA-41 & SPS \\
\hline 35 & GPHA-57 & SPS \\
\hline 36 & GPHA-13 & SPS \\
\hline 37 & GPHA-28 & SPS \\
\hline 38 & GPHA-59 & SPS \\
\hline 39 & GPH-27 & SPS \\
\hline 40 & GPHA-53 & SPS \\
\hline 41 & GPHA-32 & SPS \\
\hline 42 & GPHA-30 & SPS \\
\hline 43 & GPHA-63 & SPS \\
\hline 44 & GPHA-46 & SPS \\
\hline 45 & GPHA-47 & SPS \\
\hline 46 & GPHA-51 & SPS \\
\hline 47 & GPHA-24 & SPS \\
\hline 48 & GPHA-40 & SPS \\
\hline 49 & GPHA-64 & SPS \\
\hline 50 & GPHA-56 & SPS \\
\hline 51 & GPHA-6 & SPS \\
\hline 52 & GPHA-35 & SPS \\
\hline 53 & GPHA-25 & SPS \\
\hline 54 & GPHA-61 & SPS \\
\hline 55 & GPHA-44 & SPS \\
\hline 56 & GPHA-50 & SPS \\
\hline 57 & GPHA-19 & SPS \\
\hline 58 & GPHA-26 & SPS \\
\hline 59 & GPHA-23 & SPS \\
\hline 60 & GPHA-43 & SPS \\
\hline 61 & GPHA-29 & SPS \\
\hline 62 & GPHA-4 & SPS \\
\hline 63 & GPHA-62 & SPS \\
\hline 64 & GPHA-54 & SPS \\
\hline 65 & GPHA-65 & SPS \\
\hline 66 & GPHA-34 & SPS \\
\hline 67 & GPHA-45 & SPS \\
\hline 68 & GPHA-18 & SPS \\
\hline 69 & Adi & RV \\
\hline 70 & Megeri & $\mathrm{RV}$ \\
\hline 71 & Letu & $\mathrm{RV}$ \\
\hline
\end{tabular}

Where; SPS - Single plant selection from bulked gene pool, RV -Released Variety.

Source: - Holeta Agricultural Research Center for bulked gene pool and Kulumsa Agricultural Research Center for Released Variety.

\subsection{Experimental Design and Treatments}

Seventy one test germplasm including three control (check) varieties were evaluated in the field in an augmented block design, with four blocks containing seventeen different test germplasm per blocks. The control (check) varieties (Adi, Megeri and letu) were replicated four times in an experiment. Each plot consisted of four rows of $4 \mathrm{~m}$ length with spacing of $20 \mathrm{~cm}$ between rows and $5 \mathrm{~cm}$ between plants with a total plot area of $3.2 \mathrm{~m}^{2}$. The space between plots within block was $1 \mathrm{~m}$ and between blocks was $1.5 \mathrm{~m}$. Each row was sown 80 seeds and each plots contained total of 320 seeds. $100 \mathrm{Kg} / \mathrm{ha}$ Diammonium-phosphate (DAP) fertilizer was applied during planting weeding and all other recommended agronomic practice was followed.

\subsection{Data Collection}

Data on days to $50 \%$ flowering, days to $95 \%$ physiological maturity, 1000 seed weight (g), grain yield (kg ha-1), Ascochyta blight (1-9), and powdery mildew (1-9) were assessed on plot bases, while plant height $(\mathrm{cm})$, pods plant-1 and seeds pod-1 were recorded from five sample plants randomly selected from each plot. Mean values of the five random samples of plants plot-1 were then used for the analysis of data collected on an individual plant basis.

\subsubsection{Disease Data Scoring}

Disease reaction of individual genotypes were recorded on whole plot basis 70 days after Planting at three times (early stage, flowering and pod setting stage) based on 1-9 scale following [11] where 1 stands for immune, 2 for highly resistant, 3 for resistant, 4 for moderately resistant, 5 and 6 for moderately susceptible, 7 for susceptible, and 8 and 9 highly susceptible.

\subsubsection{Determination of Grain Yield}

The data for grain yield and other agronomic traits were taken following the standard practice for field pea trial used. Grain yield was taken as weight of seeds from all rows per plot. Grain yield adjustment was made based on oven dried seeds and adjusted to constant moisture level of $10 \%$. The total grain yield was recorded on a plot basis and converted to $\mathrm{Kg} \mathrm{ha}^{-1}$ for statistical analysis.

\subsection{Data Analysis}

The disease ratings were subjected to Friedmans nonparametric analysis of variance.

The analysis was computed based on multivariate analysis using cluster, divergence and principal component analysis.

(i) Cluster Analysis

Cluster analysis was performed based on average linkage method with Euclidean distance measure using Minitab release 17 to cluster the genotypes based on their morphoagronomic traits.

(ii) Divergence Analysis

Genetic distances between clusters as standardized 
Mahalanobis's $\mathrm{D}^{2}$ statistics were calculated as:

$$
D 2 i j=(x i-x j)^{\prime} \operatorname{cov}-1(x i-x j)
$$

Where, D2ij=the distance between cases $\mathrm{i}$ and $\mathrm{j}$; $\mathrm{xi}$ and $x j=$ vectors of the values of the variables for cases $i$ and $j$; and cov- $1=$ the pooled within groups variance-covariance matrix. The D2 values obtained for pairs of clusters were considered as the calculated values of Chi-square $\left(\mathrm{X}^{2}\right)$ and were tested for significance both at $1 \%$ and $5 \%$ probability levels against the tabulated value of $\mathrm{X}^{2}$ for ' $\mathrm{P}$ ' degree of freedom, where $\mathrm{P}$ is the number of characters considered [21].

(iii) Principal Component Analysis (PCA)

Principal component (PC) analysis was made based on the mean values for the ten traits of field pea genotypes using the PRINCOMP of the R software package in order to identify the traits that most contributed to the total variation among the genotypes

\section{Result and Discussion}

\subsection{Performance of the Genotypes}

The result of the range of parameters suggested that there were considerable differences observed in all of the traits under investigation and especially for yield, seed size, pod setting and disease response. The grain yield of the field pea genotypes ranged from 753 to $3724 \mathrm{~kg} / \mathrm{ha}$. The highest grain yield was produced by GPHA-23 $(3724 \mathrm{Kg} / \mathrm{ha})$ followed by GPHA-29 (3720Kg/ha). GPHA-9 and GPHA-19 were high yielding and resistant. Where as; GPHA-29, GPHA-48, GPHA-45 and GPHA-42 were high yielding and moderately resistant. But GPHA-23 showed high yielding potential and moderately susceptible (Table 6). Some genotypes were larger in their seed size (GPHA-30, GPHA-41, GPHA-62, GPHA-68, GPHA-9, GPHA-38, GPHA-47, GPHA-19, GPHA-18, GPHA-48, GPHA-37, GPHA-27, GPHA-57) (Table 6).

Table 2. Average Performance of the genotypes for the characters.

\begin{tabular}{|c|c|c|c|c|c|c|c|c|c|c|c|}
\hline Entry & genotype & SCAE & FD & MD & $\mathbf{P H}$ & PPP & SPP & TSW & GYKGH & $\mathbf{A B}$ & PM \\
\hline 1 & GPHA-36 & 90 & 72 & 120 & 140 & 9 & 5 & 185 & 1160 & 4 & 6 \\
\hline 2 & GPHA-3 & 86 & 73 & 121 & 150 & 13 & 6 & 191 & 2109 & 4 & 5 \\
\hline 3 & GPHA-38 & 48 & 78 & 126 & 143 & 14 & 7 & 214 & 2522 & 3 & 4 \\
\hline 4 & GPHA-68 & 90 & 78 & 125 & 138 & 15 & 5 & 220 & 2251 & 2 & 3 \\
\hline 5 & GPHA-2 & 96 & 72 & 126 & 135 & 11 & 6 & 207 & 2530 & 3 & 4 \\
\hline 6 & GPHA-58 & 91 & 72 & 117 & 120 & 11 & 5 & 154 & 2204 & 2 & 3 \\
\hline 7 & GPHA-17 & 68 & 72 & 121 & 140 & 12 & 5 & 191 & 2210 & 4 & 5 \\
\hline 8 & GPHA-7 & 80 & 77 & 118 & 120 & 11 & 5 & 189 & 2726 & 4 & 5 \\
\hline 9 & GPHA-60 & 76 & 70 & 118 & 128 & 8 & 6 & 200 & 1628 & 3 & 4 \\
\hline 10 & GPHA-11 & 80 & 73 & 119 & 137 & 9 & 5 & 151 & 2931 & 3 & 4 \\
\hline 11 & GPHA-42 & 90 & 79 & 122 & 130 & 10 & 6 & 206 & 3164 & 4 & 4 \\
\hline 12 & GPHA-48 & 90 & 79 & 122 & 160 & 13 & 6 & 211 & 3565 & 3 & 4 \\
\hline 13 & GPHA-37 & 88 & 75 & 122 & 135 & 12 & 5 & 211 & 2311 & 4 & 5 \\
\hline 14 & GPHA-15 & 92 & 74 & 119 & 137 & 8 & 5 & 191 & 2214 & 3 & 4 \\
\hline 15 & GPHA-10 & 90 & 75 & 124 & 133 & 16 & 5 & 159 & 1852 & 4 & 6 \\
\hline 16 & GPHA-67 & 90 & 78 & 125 & 133 & 11 & 5 & 134 & 1858 & 4 & 7 \\
\hline 17 & GPHA-52 & 86 & 79 & 126 & 128 & 12 & 5 & 177 & 1135 & 3 & 5 \\
\hline 18 & GPHA-1 & 90 & 79 & 125 & 120 & 10 & 6 & 143 & 2006 & 2 & 4 \\
\hline 19 & GPHA-33 & 30 & 76 & 124 & 100 & 14 & 5 & 152 & 1349 & 4 & 5 \\
\hline 20 & GPHA-8 & 85 & 80 & 123 & 133 & 9 & 5 & 150 & 2982 & 3 & 4 \\
\hline 21 & GPHA-49 & 80 & 79 & 126 & 123 & 8 & 5 & 122 & 1112 & 3 & 7 \\
\hline 22 & GPHA-21 & 93 & 80 & 125 & 117 & 8 & 4 & 124 & 1517 & 4 & 6 \\
\hline 23 & GPHA-12 & 90 & 79 & 124 & 150 & 11 & 5 & 196 & 1878 & 3 & 3 \\
\hline 24 & GPHA-14 & 94 & 79 & 124 & 137 & 12 & 6 & 163 & 1926 & 3 & 4 \\
\hline 25 & GPHA-16 & 95 & 73 & 116 & 118 & 8 & 5 & 179 & 2583 & 4 & 6 \\
\hline 26 & GPHA-39 & 65 & 79 & 121 & 133 & 12 & 6 & 161 & 1868 & 4 & 6 \\
\hline 27 & GPHA-55 & 96 & 78 & 125 & 140 & 13 & 7 & 206 & 2336 & 3 & 4 \\
\hline 28 & GPHA-9 & 94 & 79 & 124 & 130 & 9 & 7 & 216 & 3083 & 3 & 3 \\
\hline 29 & GPHA-22 & 95 & 69 & 117 & 123 & 12 & 4 & 155 & 2312 & 3 & 3 \\
\hline 30 & GPHA-20 & 95 & 75 & 118 & 137 & 15 & 5 & 155 & 2224 & 4 & 6 \\
\hline 31 & GPHA-31 & 93 & 73 & 118 & 128 & 11 & 6 & 185 & 2862 & 4 & 6 \\
\hline 32 & GPHA-5 & 51 & 74 & 121 & 108 & 10 & 5 & 174 & 1627 & 4 & 7 \\
\hline 33 & GPHA-66 & 96 & 78 & 120 & 110 & 10 & 6 & 200 & 2538 & 3 & 5 \\
\hline 34 & GPHA-41 & 83 & 75 & 125 & 118 & 7 & 6 & 224 & 2026 & 3 & 5 \\
\hline 35 & GPHA-57 & 48 & 78 & 123 & 110 & 9 & 6 & 162 & 1494 & 3 & 5 \\
\hline 36 & GPHA-13 & 40 & 81 & 125 & 128 & 10 & 6 & 156 & 2152 & 3 & 4 \\
\hline 37 & GPHA-28 & 93 & 76 & 118 & 135 & 17 & 5 & 169 & 2502 & 2 & 3 \\
\hline 38 & GPHA-59 & 96 & 74 & 118 & 125 & 11 & 6 & 179 & 2271 & 2 & 3 \\
\hline 39 & GPH-27 & 93 & 78 & 126 & 120 & 9 & 7 & 211 & 2238 & 3 & 4 \\
\hline 40 & GPHA-53 & 63 & 77 & 124 & 123 & 11 & 6 & 190 & 1956 & 3 & 4 \\
\hline 41 & GPHA-32 & 90 & 78 & 123 & 130 & 17 & 6 & 167 & 2225 & 4 & 5 \\
\hline
\end{tabular}




\begin{tabular}{|c|c|c|c|c|c|c|c|c|c|c|c|}
\hline Entry & genotype & SCAE & FD & MD & PH & PPP & SPP & TSW & GYKGH & AB & PM \\
\hline 42 & GPHA-30 & 96 & 78 & 119 & 133 & 11 & 7 & 228 & 1695 & 3 & 4 \\
\hline 43 & GPHA-63 & 96 & 71 & 122 & 118 & 15 & 6 & 209 & 1898 & 3 & 4 \\
\hline 44 & GPHA-46 & 66 & 76 & 120 & 130 & 9 & 5 & 149 & 1537 & 2 & 3 \\
\hline 45 & GPHA-47 & 93 & 76 & 126 & 140 & 12 & 6 & 214 & 2521 & 3 & 4 \\
\hline 46 & GPHA-51 & 84 & 77 & 125 & 150 & 15 & 5 & 211 & 1817 & 4 & 5 \\
\hline 47 & GPHA-24 & 93 & 72 & 115 & 100 & 9 & 6 & 148 & 1922 & 2 & 3 \\
\hline 48 & GPHA-40 & 50 & 76 & 125 & 135 & 10 & 6 & 151 & 886 & 3 & 4 \\
\hline 49 & GPHA-64 & 73 & 79 & 118 & 133 & 7 & 6 & 180 & 1880 & 3 & 4 \\
\hline 50 & GPHA-56 & 90 & 74 & 121 & 138 & 11 & 5 & 158 & 1307 & 3 & 4 \\
\hline 51 & GPHA-6 & 80 & 76 & 120 & 140 & 10 & 6 & 195 & 1735 & 2 & 3 \\
\hline 52 & GPHA-35 & 16 & 76 & 123 & 110 & 10 & 6 & 173 & 1227 & 4 & 5 \\
\hline 53 & GPHA-25 & 93 & 76 & 123 & 150 & 7 & 5 & 167 & 2182 & 4 & 7 \\
\hline 54 & GPHA-61 & 90 & 76 & 118 & 130 & 10 & 6 & 190 & 2443 & 2 & 4 \\
\hline 55 & GPHA-44 & 62 & 78 & 124 & 110 & 11 & 4 & 138 & 2243 & 2 & 3 \\
\hline 56 & GPHA-50 & 65 & 80 & 125 & 120 & 11 & 5 & 209 & 1851 & 3 & 6 \\
\hline 57 & GPHA-19 & 93 & 70 & 118 & 115 & 10 & 5 & 213 & 3412 & 2 & 3 \\
\hline 58 & GPHA-26 & 90 & 77 & 124 & 160 & 14 & 5 & 195 & 2943 & 3 & 4 \\
\hline 59 & GPHA-23 & 86 & 76 & 121 & 128 & 13 & 5 & 148 & 3724 & 3 & 5 \\
\hline 60 & GPHA-43 & 76 & 79 & 124 & 125 & 14 & 5 & 140 & 1772 & 3 & 4 \\
\hline 61 & GPHA-29 & 87 & 74 & 119 & 130 & 10 & 5 & 182 & 3720 & 3 & 4 \\
\hline 62 & GPHA-4 & 94 & 76 & 123 & 153 & 10 & 5 & 191 & 2446 & 3 & 5 \\
\hline 63 & GPHA-62 & 90 & 76 & 122 & 144 & 11 & 6 & 221 & 2294 & 4 & 5 \\
\hline 64 & GPHA-54 & 87 & 73 & 122 & 145 & 14 & 5 & 183 & 2547 & 3 & 4 \\
\hline 65 & GPHA- 65 & 86 & 73 & 123 & 135 & 15 & 5 & 157 & 1702 & 4 & 6 \\
\hline 66 & GPHA-34 & 38 & 80 & 125 & 120 & 11 & 5 & 179 & 753 & 4 & 7 \\
\hline 67 & GPHA-45 & 83 & 72 & 118 & 118 & 16 & 5 & 164 & 3306 & 3 & 4 \\
\hline 68 & GPHA-18 & 80 & 76 & 124 & 145 & 14 & 6 & 212 & 2075 & 3 & 4 \\
\hline 69 & Adi & 86 & 72 & 110 & 135 & 9 & 6 & 148 & 3068 & 3 & 3 \\
\hline 70 & Megeri & 90 & 71 & 116 & 140 & 11 & 6 & 115 & 1871 & 3 & 4 \\
\hline 71 & Letu & 83 & 73 & 114 & 130 & 10 & 6 & 139 & 2043 & 3 & 6 \\
\hline
\end{tabular}

Where; $\mathrm{SCAE}=$ Stand count at emergency (\%), DF=Days to $50 \%$ flowering (days), DM=Days to maturity (days), $\mathrm{PH}=\mathrm{Plant}$ heigh $(\mathrm{cm}), \mathrm{PPP}=\mathrm{Pods}$ per plant (number), SPP=Seeds per pod (number), TSW=Thousand seed weight (grm), GYKGH=Grain yield ( $\mathrm{Kg} / \mathrm{ha}), \mathrm{AB}=\mathrm{Ascochyta}$ blight (1-9 scale), PM=Powdery mildew (1-9 scale).

\subsection{Divergence Analysis}

\subsubsection{Cluster Analysis}

Cluster analysis grouped the 71 field pea genotypes into seven distinct classes (Figure 1). Cluster $\mathrm{C}_{1}$ constituting $8.45 \%$ of the total genotypes. This cluster constituted smaller seed size, relatively moderately resistance to ascochayta blight and moderately susceptible to powdery mildew. Cluster $\mathrm{C}_{2}$ and $\mathrm{C}_{3}$ was the largest constituting $36.5 \%$ and $35.2 \%$ of the total genotypes respectively. Clusters $C_{2}$ and $C_{3}$ were characterized by genotypes with an intermediate number of pods plant ${ }^{-1}$ and medium maturity. Clusters $\mathrm{C}_{4}, \mathrm{C}_{5}$ and $\mathrm{C}_{6}$, and $\mathrm{C}_{7}$ constituted $9.86 \%, 4.23 \%$ and $2.82 \%$ of the total genotypes, respectively. Genotypes with more number of stands, low number of pods plant ${ }^{-1}$ and high number of seeds pod $^{-1}$ were grouped in $\mathrm{C}_{4}$. Cluster five constituted high yielding genotypes with taller plant height and an intermediate number of pods plant- ${ }^{1}$. Genotypes with less number of stands, lately flower and, mature and low yielding genotypes were categorized under $\mathrm{C}_{6}$. Whereas, the seventh cluster characterized by short plant height, a higher number of pods plant $^{-1}$, larger seed size but a lower number of seeds $\operatorname{pod}^{-1}$, early flower and, mature, relatively high yielding potential, relatively resistance and moderately resistance to ascochayta blight and powdery mildew respectively (Table 3 ).

\subsubsection{Estimation of Inter and Intra Cluster Distance}

The genetic divergence between all possible pairs of clusters were highly significant $(\mathrm{P}<0.01)$. Different members within a cluster being assumed to be more closely related in terms of the trait under consideration with each other than those members in different clusters [14]. The maximum distance was found between cluster five and six $\left(D^{2}=2850.61\right) \quad$ (Table 4). Cluster five constitutes three genotypes while cluster six constitutes two genotypes. The second most divergent clusters were cluster six and seven $\left(D^{2}=2540.12\right)$. Cluster seven constitutes two genotypes. The third most divergent clusters were cluster one and five $\left(D^{2}=2454.89\right)$. Cluster one constituting from six genotypes. The forth most diver-gent clusters were between cluster four and six $\left(D^{2}=2185.50\right)$. Cluster four contain seven genotypes and so on, indicated the wide diversity of the genotypes. Genotypes grouped into the same cluster also presumably diverge little from one another as the aggregate characters are measured. Different authors reported the presence of diversity among field pea genotypes classifying in different number of distinct clusters. In the present study; therefore, crossing of genotypes from cluster five and six will give rise to maximum genetic segregation. All clusters showed zero intra-cluster $\mathrm{D}^{2}$ value (Table 4). This 
result revealed; the genotypes grouped within the cluster are more similar with each other.

Table 3. Mean of genetic divergence in morpho-agronomic traits of the seven clusters of 71 field pea genotypes studied.

\begin{tabular}{lllllllll}
\hline Character & I & II & III & IV & V & VI & VII & Grand Mean \\
\hline SCAE & 65.33 & 80.27 & 86.04 & $88.29^{* *}$ & 87.67 & $44.0^{*}$ & 88 & 81.34 \\
FD & 76 & 76.04 & 75.56 & 76.14 & 76.33 & $78.0^{* *}$ & $71.00^{*}$ & 75.8 \\
MD & 123.33 & 121.73 & 121.52 & 120 & 120.67 & $125.0^{* *}$ & $118.00^{*}$ & 121.56 \\
PH & 123.17 & 129.19 & 132.24 & 136.14 & $139.33^{* *}$ & 127.5 & $116.50^{*}$ & 130.46 \\
PPP & 10.67 & 11.12 & 11.64 & $10.14^{*}$ & 12 & 10.5 & $13.00^{* *}$ & 11.24 \\
SPP & 5.17 & 5.62 & 5.48 & $5.71 * *$ & 5.33 & 5.5 & $5.00^{*}$ & 5.51 \\
TSW & $161.17^{*}$ & 173.58 & 186.32 & 178.71 & 180.33 & 165 & $188.50^{* *}$ & 177.99 \\
GYKGH & 1215.05 & 1828.63 & 2361.04 & 3004.48 & $3669.71^{* *}$ & $819.5^{*}$ & 3359.09 & 2172.65 \\
AB & $3.50^{* *}$ & 3.15 & 3.08 & 3.29 & 3 & $3.5^{* *}$ & $2.50^{*}$ & 3.15 \\
PM & 5.33 & 4.69 & 4.32 & 4 & 4.33 & $5.5^{* *}$ & $3.50^{*}$ & 4.52 \\
\hline
\end{tabular}

Where; $\mathrm{SCAE}=\mathrm{Stand}$ count at emergency (\%), DF=Days to $50 \%$ flowering (days), DM=Days to maturity (days), $\mathrm{PH}=\mathrm{Plant}$ heigh $(\mathrm{cm}$ ), $\mathrm{PPP}=\mathrm{Pods}$ per plant (number), SPP=Seeds per pod (number), TSW=Thousand seed weight (grm), GYKGH=Grain yield (Kg/ha), AB=Ascochyta blight (1-9 scale), PM=Powdery mildew (1-9 scale).

Table 4. Pair wise generalized squared distance $\left(D^{2}\right)$ among 7 clusters constructed from seventy one field pea genotypes.

\begin{tabular}{|c|c|c|c|c|c|c|c|c|}
\hline & $\mathrm{C}_{1}$ & $\mathrm{C}_{2}$ & $\mathrm{C}_{3}$ & $\mathrm{C}_{4}$ & $\mathrm{C}_{5}$ & $\mathrm{C}_{6}$ & $\mathbf{C}_{7}$ & Average $\mathrm{D}^{2}$ \\
\hline $\mathrm{C}_{1}$ & 0 & $613.91 * *$ & $1146.49 * *$ & $1789.71 * *$ & $2454.89 * *$ & $396.18 * *$ & $2144.35^{* *}$ & 92.472 \\
\hline $\mathrm{C}_{2}$ & & 0 & $532.61 * *$ & $1175.92 * *$ & $1841.14 * *$ & $1009.82 * *$ & $1530.62 * *$ & 143.644 \\
\hline $\mathrm{C}_{3}$ & & & 0 & $643.5^{* *}$ & $1308.7^{* *}$ & $1542.28 * *$ & $998.19 * *$ & 143.93 \\
\hline $\mathrm{C}_{4}$ & & & & 0 & $665.24 * *$ & $2185.5^{* *}$ & $355.34 * *$ & 92.708 \\
\hline $\mathrm{C}_{5}$ & & & & & 0 & $2850.61 * *$ & $311.63 * *$ & 75.743 \\
\hline $\mathrm{C}_{6}$ & & & & & & 0 & $2540.12 * *$ & 68.815 \\
\hline $\mathrm{C}_{7}$ & & & & & & & 0 & 58.376 \\
\hline
\end{tabular}

$* *=$ highly significant at $(\mathrm{P} \leq 0.01)$ chi-square $(\times 2)=23.21$.

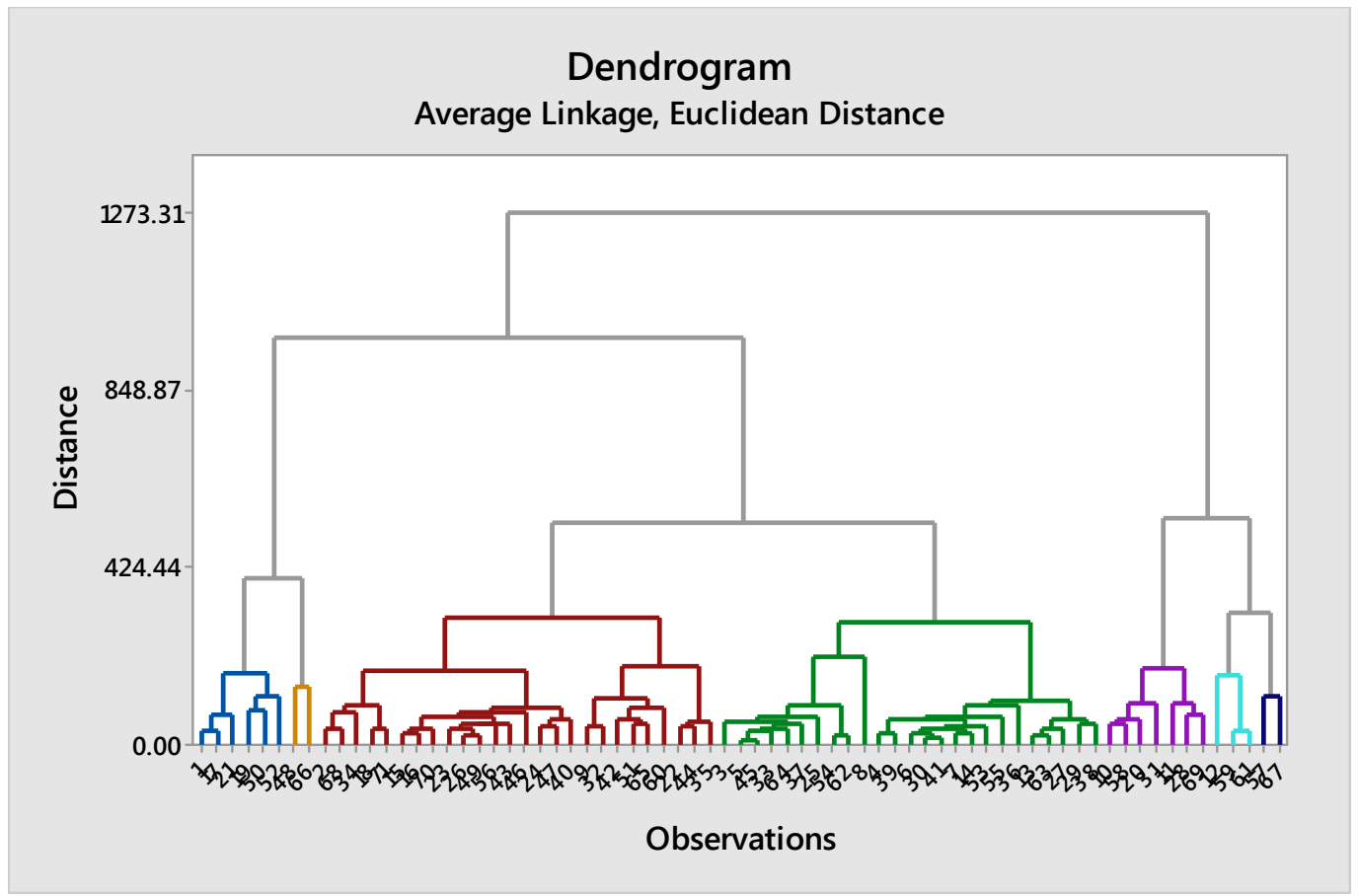

Figure 1. Dendrogram of 71 field pea genotypes based on ten morpho-agronomic traits using Euclidean distance matrix (The dendrogram represent cluster one $=6$ genotypes, cluster six $=2$ genotypes, cluster two $=26$ genotypes, cluster three $=25$ genotypes, cluster four $=7$ genotypes, cluster five $=3$ genotypes and cluster seven $=2$ genotypes respectively).

\subsection{Contribution of the Component Characters to Genetic Diversity}

All the traits were subjected to principal component analysis (PCA) for estimation of weight contribution of each trait and to evaluate the total level of genetic diversity. Four components gave Eigenvalues $>1.0$, thus they were important in consideration of genetic variability amongst all the genotypes. Four components (PC1-PC4) contributed 68.45\% genetic variability (Table 5). The importance of this technique has been reported appreciably for selecting field 
pea lines for high yielding and powdery mildew resistance [2]. The PC1 explained $23.4 \%$ of the total variability. Powdery mildew, days to mature, days to flower, ascocayta blight were the variables with the largest positive loadings in their order. However, grain yield and stand count with negatively loading was observed for this component. The PC2 explained $18.5 \%$ of the total contribution toward variability. Thousand seed weight, plant height, days to mature, days to flower and seed per pod were the variables in their order with high positive loading. The third component (PC3) contributed $15 \%$ of variability with ascochayta blight, powdery mildew and plant height was variables in their order with high positive loading but negatively for days to flowering and seed per pod. The PC4 explained $11.5 \%$ of the total variance and related to high positive loadings for seed per pod and powdery mildew along with negative loadings for pod per plant and days to maturity.

Table 5. Principal component analysis (PCA) of 10 traits among pea genotypes, Eigen values, percentage variability explained by first four components.

\begin{tabular}{|c|c|c|c|c|}
\hline Trait & PC1 & PC2 & PC3 & PC4 \\
\hline Stand count & $-.415107 * *$ & 0.126941 & 0.317062 & 0.054206 \\
\hline Days to flower & $0.358732 *$ & $0.348916^{*}$ & $-.250219 * *$ & -0.0966 \\
\hline Days to mature & $0.375201 *$ & $0.432508^{*}$ & -0.16865 & $-.277857 * *$ \\
\hline Plant height $(\mathrm{cm})$ & -0.13362 & $0.444120^{*}$ & $0.372104 *$ & -0.04028 \\
\hline No. of pods per plant & -0.06033 & 0.251607 & 0.22596 & $-.644759 * *$ \\
\hline No. of seeds per pod & -0.088 & $0.340741 *$ & $-.336310 * *$ & $0.515947 *$ \\
\hline Thousend Seed weight (gm) & -0.18747 & $0.519140^{*}$ & -0.10924 & 0.245362 \\
\hline Grain yield/ha $(\mathrm{Kg})$ & $-.434838 * *$ & 0.144765 & 0.168257 & 0.034232 \\
\hline Ascocayta blight (1-9 score) & $0.353656^{*}$ & 0.089166 & $0.520427 *$ & 0.226313 \\
\hline Powdery mildew (1-9 score) & $0.423891 *$ & -0.00355 & $0.441257 *$ & $0.338225^{*}$ \\
\hline Eigenvalue & 2.34014 & 1.84884 & 1.50694 & 1.14878 \\
\hline Percent variability & 0.234 & 0.1849 & 0.1507 & 0.1149 \\
\hline Commulative variability & 0.234 & 0.4189 & 0.5696 & 0.6845 \\
\hline
\end{tabular}

\subsection{Response of Genotypes for Powdery Mildew Resistance}

The field pea genotypes were screened under field condition for natural infection against powdery mildew disease caused by Erysiphe pisi at three growth stages. The severity of the disease was increased from early to flowering and to pod setting stages.

All tested genotypes differed significantly for their response to powdery mildew disease. Hence forward, it was found that out of the total 71 field pea genotypes, thirteen genotypes (GPHA-12, GPHA-9, GPHA-22, GPHA-44, GPHA-19, GPHA-68, GPHA-58, GPHA-28, GPHA-59, GPHA-46, GPHA-24, GPHA-6, ADI) were resistant (Disease Severity Scale-3), twenty nine (GPHA-14, GPHA55, GPHA-61, GPHA-26, GPHA-43, GPHA-29, GPHA-54, GPHA-45, GPHA-18, GPHA-38, GPHA-2, GPHA-60, GPHA-11, GPHA-42, GPHA-48, GPHA-15, GPHA-1, GPHA-8, GPHA-13, GPHA-27, GPHA-53, GPHA-30, GPHA-63, GPHA-47, GPHA-40, GPHA-64, GPHA-56, Adi and Megeri ) were moderately resistant (Disease Severity Scale -4), twenty five (GPHA-21, GPHA-16, GPHA-39, GPHA-20, GPHA-31, GPHA-66, GPHA-41, GPHA-57, GPHA-50, GPHA-23, GPHA-4, GPHA-62, GPHA-65, GPHA-36, GPHA-3, GPHA-17, GPHA-7, GPHA-37, GPHA-10, GPHA-52, GPHA-33, GPHA-32, GPHA-51, GPHA-35, LETU) were moderately susceptible.

(Disease Severity Scale -5 \&6), and seven (GPHA-49, GPHA-5, GPHA-34, GPHA-67, GPHA-25) were susceptible (Disease Severity Scale -7) (Table 6). [2] was found that out of the 24 pea lines, three lines (PL-4, PL-5 and PL-23) were highly resistant, seven (PL-1, PL-2, PL-3, PL-6, PL-11, PL16 and PL-19) were rated as resistant and three (PL-10, PL12 and PL-13) were moderately resistant.

Research reports also indicated that some materials introduced from Australia, especially cultivar cooke that have resistance for powdery mildew in Ethiopia and there is genetic diversity in resistance to powdery mildew in Ethiopian landrace collections [16].

table 6. Response of different field pea genotypes screened against powdery mildew under field condition at different growth stages.

\begin{tabular}{|c|c|c|c|c|c|}
\hline \multirow{3}{*}{ Entry } & \multirow{3}{*}{ Genotype } & \multirow{2}{*}{$\begin{array}{l}\text { Disease } \\
\text { severity at }\end{array}$} & \multirow{2}{*}{$\begin{array}{l}\text { Disease } \\
\text { severity at flowering stage }\end{array}$} & \multirow{2}{*}{$\begin{array}{l}\text { Disease } \\
\text { severity at pod setting }\end{array}$} & \multirow{3}{*}{$\begin{array}{l}\text { Disease } \\
\text { Response } \\
\text { (at the last stage) }\end{array}$} \\
\hline & & & & & \\
\hline & & early stage (1-9) & $(1-9)$ & stage (1-9) & \\
\hline 1 & GPHA-36 & 2 & 5 & 6 & MS \\
\hline 2 & GPHA-3 & 2 & 5 & 5 & MS \\
\hline 3 & GPHA-38 & 3 & 4 & 4 & MR \\
\hline 4 & GPHA-68 & 3 & 3 & 3 & $\mathrm{R}$ \\
\hline 5 & GPHA-2 & 3 & 3 & 4 & MR \\
\hline 6 & GPHA-58 & 2 & 3 & 3 & $\mathrm{R}$ \\
\hline 7 & GPHA-17 & 2 & 5 & 5 & MS \\
\hline 8 & GPHA-7 & 3 & 4 & 5 & MS \\
\hline 9 & GPHA-60 & 2 & 3 & 4 & MR \\
\hline 10 & GPHA-11 & 3 & 4 & 4 & MR \\
\hline 11 & GPHA-42 & 3 & 4 & 4 & MR \\
\hline
\end{tabular}




\begin{tabular}{|c|c|c|c|c|c|}
\hline \multirow{3}{*}{ Entry } & \multirow{3}{*}{ Genotype } & \multirow{3}{*}{$\begin{array}{l}\text { Disease } \\
\text { severity at } \\
\text { early stage (1-9) } \\
\end{array}$} & \multirow{2}{*}{$\begin{array}{l}\text { Disease } \\
\text { severity at flowering stage }\end{array}$} & \multirow{2}{*}{$\begin{array}{l}\text { Disease } \\
\text { severity at pod setting }\end{array}$} & \multirow{3}{*}{$\begin{array}{l}\text { Disease } \\
\text { Response } \\
\text { (at the last stage) } \\
\end{array}$} \\
\hline & & & & & \\
\hline & & & $(1-9)$ & stage (1-9) & \\
\hline 12 & GPHA-48 & 3 & 4 & 4 & MR \\
\hline 13 & GPHA-37 & 2 & 4 & 5 & MS \\
\hline 14 & GPHA-15 & 3 & 4 & 4 & MR \\
\hline 15 & GPHA-10 & 2 & 5 & 6 & MS \\
\hline 16 & GPHA-67 & 3 & 7 & 7 & S \\
\hline 17 & GPHA-52 & 3 & 4 & 5 & MS \\
\hline 18 & GPHA-1 & 3 & 4 & 4 & MR \\
\hline 19 & GPHA-33 & 3 & 5 & 5 & MS \\
\hline 20 & GPHA-8 & 3 & 4 & 4 & MR \\
\hline 21 & GPHA-49 & 2 & 6 & 7 & S \\
\hline 22 & GPHA-21 & 3 & 5 & 6 & MS \\
\hline 23 & GPHA-12 & 2 & 3 & 3 & $\mathrm{R}$ \\
\hline 24 & GPHA-14 & 3 & 4 & 4 & MR \\
\hline 25 & GPHA-16 & 3 & 5 & 6 & MS \\
\hline 26 & GPHA-39 & 3 & 5 & 6 & MS \\
\hline 27 & GPHA-55 & 3 & 4 & 4 & MR \\
\hline 28 & GPHA-9 & 3 & 3 & 3 & $\mathrm{R}$ \\
\hline 29 & GPHA-22 & 2 & 3 & 3 & $\mathrm{R}$ \\
\hline 30 & GPHA-20 & 2 & 5 & 6 & MS \\
\hline 31 & GPHA-31 & 3 & 5 & 6 & MS \\
\hline 32 & GPHA-5 & 3 & 6 & 7 & S \\
\hline 33 & GPHA-66 & 2 & 4 & 5 & MS \\
\hline 34 & GPHA-41 & 2 & 4 & 5 & MS \\
\hline 35 & GPHA-57 & 3 & 4 & 5 & MS \\
\hline 36 & GPHA-13 & 3 & 4 & 4 & MR \\
\hline 37 & GPHA-28 & 3 & 3 & 3 & $\mathrm{R}$ \\
\hline 38 & GPHA-59 & 3 & 3 & 3 & $\mathrm{R}$ \\
\hline 39 & GPHA-27 & 3 & 4 & 4 & MR \\
\hline 40 & GPHA-53 & 3 & 4 & 4 & MR \\
\hline 41 & GPHA-32 & 2 & 4 & 5 & MS \\
\hline 42 & GPHA-30 & 3 & 4 & 4 & MR \\
\hline 43 & GPHA-63 & 3 & 3 & 4 & MR \\
\hline 44 & GPHA-46 & 2 & 3 & 3 & $\mathrm{R}$ \\
\hline 45 & GPHA-47 & 3 & 4 & 4 & MR \\
\hline 46 & GPHA-51 & 3 & 4 & 5 & MS \\
\hline 47 & GPHA-24 & 3 & 3 & 3 & $\mathrm{R}$ \\
\hline 48 & GPHA-40 & 3 & 4 & 4 & MR \\
\hline 49 & GPHA-64 & 3 & 4 & 4 & MR \\
\hline 50 & GPHA-56 & 3 & 4 & 4 & MR \\
\hline 51 & GPHA-6 & 2 & 3 & 3 & $\mathrm{R}$ \\
\hline 52 & GPHA-35 & 2 & 4 & 5 & MS \\
\hline 53 & GPHA-25 & 3 & 5 & 7 & S \\
\hline 54 & GPHA-61 & 2 & 3 & 4 & MR \\
\hline 55 & GPHA-44 & 3 & 3 & 3 & $\mathrm{R}$ \\
\hline 56 & GPHA-50 & 2 & 6 & 6 & MS \\
\hline 57 & GPHA-19 & 2 & 3 & 3 & $\mathrm{R}$ \\
\hline 58 & GPHA-26 & 3 & 4 & 4 & MR \\
\hline 59 & GPHA-23 & 2 & 5 & 5 & MS \\
\hline 60 & GPHA-43 & 2 & 4 & 4 & MR \\
\hline 61 & GPHA-29 & 3 & 4 & 4 & MR \\
\hline 62 & GPHA-4 & 3 & 5 & 5 & MS \\
\hline 63 & GPHA-62 & 3 & 5 & 5 & MS \\
\hline 64 & GPHA-54 & 3 & 4 & 4 & MR \\
\hline 65 & GPHA-65 & 3 & 6 & 6 & MS \\
\hline 66 & GPHA-34 & 3 & 6 & 7 & S \\
\hline 67 & GPHA-45 & 2 & 4 & 4 & MR \\
\hline 68 & GPHA-18 & 3 & 4 & 4 & MR \\
\hline 69 & Adi & 2 & 4 & 3 & MR \\
\hline 70 & megeri & 3 & 4 & 4 & MR \\
\hline 71 & Letu & 4 & 5 & 6 & MS \\
\hline
\end{tabular}




\section{Conclusion}

Results from present study revealed that a considerable level of genetic diversity and variation for resistance against powdery mildew was found indicating the potential of selection for promising gene pools which could be exploited as direct sources or may be transferred through hybridization.

Among the 10 studied traits, four (Eigenvalue >1.0) contributed more than $68.45 \%$ variability among the materials Cluster analysis grouped the 71 field pea genotypes into seven distinct classes. The genetic divergence between all possible pairs of clusters were highly significant $(\mathrm{P}<0.01)$. The maximum distance was found between cluster five and six. Therefore, selecting and crossing of genotypes from cluster five and six will give rise to maximum genetic segregation.

GPHA-29, GPHA-48, GPHA-45 and GPHA-42 genotypes were found to be high yielding and powdery mildew moderately resistant and GPHA-9 and GPHA-19 genotypes were also high yielding and resistant; they could be selected as elite genotypes pass to the next stage. High yielding and resistant gene pools (GPHA-9 and GPHA-19) and low yielding and resistant gene pools (GPHA-12, GPHA-22, GPHA-44, GPHA-68, GPHA-58, GPHA-28, GPHA-59, GPHA-46, GPHA-24, GPHA-6) could be selected as elite genotypes for breeding (crossing) purpose. However, the present result was from one location and one year (season) data; it is recommended to repeat under wide range of agroclimatic conditions in a number of locations and seasons to evaluate their yielding potential, yield and disease stability to confirm with the present finding.

\section{References}

[1] Adisu T and Ermiyas T (2017). Grain Yield and Yield Components of Field Pea (Pisum sativumL.): As influenced by Ascochyta Blight (Mycosphaerella pinodes) Disease in the Highlands of Bale, Oromia. American Scientific Research Journal for Engineering, Technology and Sciences (ASRJETS), 35 (1): 15-24.

[2] Ajmal I, Shahen S, Mohammad N Abdul G (2017). Morphological Characterization and Selection for High Yielding and Powdery Mildew Resistant Pea (Pisum Sativum L.). Sains Malaysiana 46 (10): 1727-34.

[3] Ateet M, Bhupendra B, Raju PA, Sagar GC, Swati S (2015). Efficacy assessment of treatment methods against powdery mildew disease of pea (Pisum sativum L.) caused by Erysiphe pisi var. pisi. World Journal of Agricultural Research, 3 (6): 185-191.

[4] Aysh FM (2013). Inheritance and association of quantitative characteristics in Syrian landraces of garden peas (Pisum sativum L.). An International Journal of Life Sciences 2 (3): 198-203.

[5] Bhattacharjee R, Dey U (2014). An overview of fungal and bacterial bio pesticides to control plant pathogens/disease/. African Journal of Microbial Research 8 (17): 1749-1762.

[6] CSA (Central Statistical Authority). 2018. Agricultural sample survey 2009/10. Report on area and production of major crops private peasant holdings, Meher Season. Addis Ababa. Statistical Bulletin no. 586. Volume 1.

[7] Eklund M, Von PR, Dayteg C, Henriksson T, Weibull P, Ceplitis A, Isaac P, Tuvesson, S (2005). Microsatellite markers for powdery mildew resistance in pea (Pisum sativum L.). Hereditas 142: 86-91.

[8] FAOSTAT (2017). Food and Agriculture Organization of the United Nations. Available online at http://www:fao.org/faostat/en/\#data/QC/visualize.

[9] Fondevilla S. Rubiales D (2012). Powdery mildew control in pea. A review. Agronony and sustainable. development. 32: 401-409.

[10] Ghafoor A, Mcphee K. (2012). Marker assisted selection (MAS) for developing powdery mildew resistant pea cultivars. Euphytica 186: 593-607.

[11] Little TM and Hills FJ (1978). Agricultural Experimentation, Design and Analysis. pp. 162 - 163. John Wiley and Sons Inc., New York.

[12] Mahbub MM, Rahman MM, Hossain MS, Nahar L, Shirazy BJ. 2016. Morphophysiological Variation in Soybean (Glycine max (L.) Merrill). American-Eurasian Journal of Agricultural \& Environmental Sciences 16 (2): 234-238.

[13] Messiaen CM, Seif AA, Jarso M, Keneni GA (2006). Pisum sativum L. internet record from PROTA4U. In: Brink M, Belay G (Eds.), PROTA: Plant Resources of Tropical Africa, Wageningen, Netherlands.

[14] Million F (2012). Variablity, Heriatablity and Associattion of Some Morpho-Agronomic Traits in Field Pea (Pisium Sativum L.) Genotypes. Pakistan Journal of Bilogical Science 15 (80); 358-366.

[15] Mussa J, Tezera W, Gemechu K (2006). Review of field pea (Pisum sativum L.) genetics and breeding research in Ethiopia: A review. In. Kemal A, Gemechu K, Seid A, Malhotra R, Beniwal S (Eds.), Food and Forage Legumes of Ethiopia: Progress and Prospects. Addis Ababa, Ethiopia, pp. 67-79.

[16] Mussa J, Dereje G, Gemechu K (2009). Procedures of Field Pea Improvement through Hybridization. Technical Manual No. 22, Ethiopian Institute of Agricultural Research. p 12.

[17] Nigussie T, Seid A, Derje G, Tesfaye B, Chemeda F, Adane A, Abiy T, Fekede A, Kiros M (2008). Review of Research on Diseases Food Legumes. Abraham Tadesse (Eds). Increasing crop production through improved plant protection. (1): 85-124.

[18] Nisar M, Ghafoor A, Khan MR, Qureshi AS (2006). Screening of Pisum sativum L. germplasm against Erysiphe pisi. Botany 48 (2): 33-37.

[19] Rahman MM, Syed M, Akter A, Alam MM, Ahsan MM. 2014. Genetic Variability, Correlation and Path Coefficient Analysis of Morphological Traits in Transplanted Aman Rice (Oryza sativa L.). American-Eurasian Journal of Agricultural \& Environmental Science 14 (5): 387-391.

[20] Sahile S, Ahmed S, Fininsa C, Abang M and Sakhuja PK (2008). Survey of chocolate spot (Botrytis fabae) disease of faba bean (Vicia faba L.) and assessment of factors influencing disease epidemics in northern Ethiopia. Crop Protection, 27: 1457-1463. 
[21] Singh RK, Chaudhary BD (1999). Biometrical Methods in Quantitative Genetics Analysis. Kalyani publishers, New Delhi. Pp 318.

[22] Teshome E, and Tegegn A (2017). Comparative Study of Powdery Mildew (Erysiphe polygoni) Disease Severity and Its Effect on Yield and Yield Components of Field Pea (Pisum sativum L.) in the Southeastern Oromia, Ethiopia. Journal of
Plant Pathol ogy and Microbiology, 8: 410. doi: 10.4172/2157-7471.1000410.

[23] Tomooka N. 1991. Genetic diversity and landrace differentiation of mungbean, Vigna radiata (L.) Wilczek, and evaluation of its wild relatives (the subgenus Ceratotropis) as breeding materials. Technical bulletin of the Tropical Agriculture Research Center. 